\title{
Local Convergence Analysis of an Efficient Fourth Order Weighted-Newton Method under Weak Conditions
}

\author{
Ioannis K. Argyros ${ }^{1}$ and Santhosh George ${ }^{2}$
}

\begin{abstract}
Local convergence analysis of a fourth order method considered by Sharma et. al in [19] for solving systems of nonlinear equations. Using conditions on derivatives upto the order five, they proved that the method is of order four. In this study using conditions only on the first derivative, we prove the convergence of the method in [19]. This way we extended the applicability of the method. Numerical example which do not satisfy earlier conditions but satisfy our conditions are presented in this study.
\end{abstract}

AMS Subject Classification (2000). 65D10, 65D99, 65J20, 49M15, 74G20, 41A25.

Keywords. local convergence, weighted Newton method, Fréchet derivative.

\footnotetext{
${ }^{1}$ Department of Mathematical Sciences, Cameron University, USA, iargyros@cameron.edu

${ }^{2}$ Department of Mathematical and Computational Sciences, National Institute of Technology, Karnataka, India, sgeorge@nitk.ac.in
} 


\section{Introduction}

In [19], Sharma et. al, studied the iterative method defined by

$$
\begin{aligned}
y_{n} & =x_{n}-\frac{2}{3} F^{\prime}\left(x_{n}\right)^{-1} F\left(x_{n}\right) \\
x_{n+1} & =y_{n}-A_{n} F^{\prime}\left(x_{n}\right)^{-1} F\left(x_{n}\right),
\end{aligned}
$$

where $x_{0}$ is the initial point and

$$
A_{n}=\frac{1}{2}\left[-I+\frac{9}{4} F^{\prime}\left(y_{n}\right)^{-1} F^{\prime}\left(x_{n}\right)+\frac{3}{4} F^{\prime}\left(x_{n}\right)^{-1} F^{\prime}\left(y_{n}\right)\right]
$$

for approximating the solution $x^{*}$ of

$$
F(x)=0,
$$

when $F: D \subseteq \mathbb{R}^{i} \rightarrow \mathbb{R}^{j}$ is a continuously differentiable operator. Using Taylors expansion and assumptions on the derivatives up to fifth order, they have proved that the sequence $\left\{x_{n}\right\}$ defined by the method (1.1) converges to $x^{*}$ with an order of convergence four. Due to the wide range of applications, the study of (1.2) is an important problem in mathematics [1-22]. But the conditions on the higher order derivatives, restrict the applicability of method (1.1) to solve (1.2) (see the numerical examples).

In this study we consider the method (1.1) for approximating a solution $x^{*}$ of (1.2) by when $F: D \subseteq \mathcal{B}_{1} \rightarrow \mathcal{B}_{2}$ is a continuously Fréchet differentiable operator. Here $\mathcal{B}_{1}, \mathcal{B}_{2}$ are Banach spaces. Let $B(a, \rho), \bar{B}(a, \rho)$ stand respectively for the open and closed balls in $\mathcal{B}_{1}$ with center $a \in \mathcal{B}_{1}$ and of radius $\rho>0$.

Next, we shall give an example to show that method (1.1) cannot be applied if we use the analysis in [19].

EXAMPLE 1.1. Let $\mathcal{B}_{1}=\mathcal{B}_{2}=C[0,1], D=\bar{B}\left(x^{*}, 1\right)$ and consider the nonlinear integral equation of the mixed Hammerstein-type $[1,2,6-9,12]$ defined by

$$
x(s)=\int_{0}^{1} G(s, t)\left(x(t)^{3 / 2}+\frac{x(t)^{2}}{2}\right) d t,
$$

where the kernel $G$ is the Green's function defined on the interval $[0,1] \times[0,1]$ by

$$
G(s, t)= \begin{cases}(1-s) t, & t \leq s \\ s(1-t), & s \leq t .\end{cases}
$$

The solution $x^{*}(s)=0$ is the same as the solution of equation (1.2), where $F: C[0,1] \longrightarrow C[0,1])$ is defined by

$$
F(x)(s)=x(s)-\int_{0}^{1} G(s, t)\left(x(t)^{3 / 2}+\frac{x(t)^{2}}{2}\right) d t .
$$


Vol. LVI (2018) Local Convergence Analysis of an Efficient Fourth Order Method 25

Notice that

$$
\left\|\int_{0}^{1} G(s, t) d t\right\| \leq \frac{1}{8}
$$

Then, we have that

$$
F^{\prime}(x) y(s)=y(s)-\int_{0}^{1} G(s, t)\left(\frac{3}{2} x(t)^{1 / 2}+x(t)\right) d t,
$$

so since $F^{\prime}\left(x^{*}(s)\right)=I$,

$$
\left\|F^{\prime}\left(x^{*}\right)^{-1}\left(F^{\prime}(x)-F^{\prime}(y)\right)\right\| \leq \frac{1}{8}\left(\frac{3}{2}\|x-y\|^{1 / 2}+\|x-y\|\right) .
$$

One can see that, higher order than $F^{\prime}$ derivatives of $F$ do not exist in this example, so the method (1.1) cannot be applied if we use the analysis in [19]. Later in Section 3 we show that indeed one can use the method (1.1) to solve the above equation.

Our goal is to weaken the assumptions in [19] and apply the method (1.1) for solving equation (1.2) in Banach spaces, so that the applicability of the method (1.1) can be extended.

In Section 2, we present the local convergence of method (1.1). Numerical examples are given in the last section of the paper.

\section{Local convergence}

Let $w_{0}: \mathbb{R}_{+} \cup\{0\} \longrightarrow \mathbb{R}_{+} \cup\{0\}$ be a continuous and nondecreasing function with $w(0)=0$ and let

$$
r_{0}=\sup \left\{t \geq 0: w_{0}(t)<1\right\} .
$$

Let $w, v:\left[0, r_{0}\right) \longrightarrow \mathbb{R}_{+} \cup\{0\}$ be continuous and nondecreasing functions with $w(0)=0$. Define functions $\varphi_{1}$ and $\psi_{1}$ on the interval $\left[0, r_{0}\right)$ by

$$
\varphi_{1}(t)=\frac{\int_{0}^{1} w((1-\theta) t) d \theta+\frac{1}{3} \int_{0}^{1} v(\theta t) d \theta}{1-w_{0}(t)},
$$

and

$$
\psi_{1}(t)=\varphi_{1}(t)-1
$$

Suppose that

$$
v(0)<3 \text {. }
$$


Then, by the definition of $r_{0}, \varphi_{1}, \psi_{1}$ and $(2.2)$, we have $\psi_{1}(0)=\frac{v(0)}{3}-1<0$ and $\psi_{1}(t) \rightarrow+\infty$ as $t \rightarrow r_{0}^{-}$. By applying the intermediate value theorem on function $\psi_{1}$ on the interval $\left[0, r_{0}\right]$, we get that function $\psi_{1}$ has zeros in the interval $\left(0, r_{0}\right)$. Denote by $r_{1}$ the smallest such zero. Define also parameters $\bar{r}_{0}$ by

$$
\bar{r}_{0}=\max \left\{t \in\left[0, r_{0}\right]: w_{0}\left(\varphi_{1}(t) t\right)<1\right\} .
$$

Furthermore, define functions $\varphi_{2}$ and $\psi_{2}$ on the interval $\left[0, \bar{r}_{0}\right)$ by

$$
\begin{aligned}
\varphi_{2}(t)= & \frac{\int_{0}^{1} w((1-\theta) t) d \theta}{1-w_{0}(t)} \\
& +\frac{9}{8} \frac{\left(w_{0}(t)+w_{0}\left(\varphi_{1}(t) t\right)\right) \int_{0}^{1} v(\theta t) d \theta}{\left(1-w_{0}(t)\right)\left(1-w_{0}\left(\varphi_{1}(t) t\right)\right)} \\
& +\frac{3}{8} \frac{\left(w_{0}(t)+w_{0}\left(\varphi_{1}(t) t\right)\right) \int_{0}^{1} v(\theta t) d \theta}{\left(1-w_{0}(t)\right)^{2}}
\end{aligned}
$$

and

$$
\psi_{2}(t)=\varphi_{2}(t)-1
$$

Then, we have that $\varphi_{2}(0)=-1<0$ and $\varphi_{2}(t) \longrightarrow+\infty$ as $t \longrightarrow \bar{r}_{0}^{-}$. Denote by $r_{2}$ the smallest zero of function $\varphi_{2}$ on the interval $\left(0, \bar{r}_{0}\right)$. Define the radius of convergence $r$ by

$$
r=\min \left\{r_{1}, r_{2}\right\}
$$

Then, we have that for each $t \in[0, r)$

$$
0 \leq \varphi_{i}(t)<1, \quad i=1,2
$$

We shall use the conditions denoted by $(\mathcal{C})$ in our local convergence analysis of method (1.1):

$\left(\mathcal{C}_{1}\right) F: D \subset \mathcal{B}_{1} \longrightarrow \mathcal{B}_{2}$ is a continuously Fréchet-differentiable operator;

$\left(\mathcal{C}_{2}\right)$ there exists $x^{*} \in D$ such that $F\left(x^{*}\right)=0$ and $F^{\prime}\left(x^{*}\right)$ is invertible;

$\left(\mathcal{C}_{3}\right)$ there exists function $w_{0}: \mathbb{R}_{+} \cup\{0\} \longrightarrow \mathbb{R}_{+} \cup\{0\}$ continuous and nondecreasing with $w_{0}(0)=0$ such that for each $x \in D$

$$
\left\|F^{\prime}\left(x^{*}\right)^{-1}\left(F^{\prime}(x)-F^{\prime}\left(x^{*}\right)\right)\right\| \leq w_{0}\left(\left\|x-x^{*}\right\|\right) .
$$

Set $D_{0}=D \cap B\left(x^{*}, r_{0}\right)$, where $r_{0}$ is given by (2.1). 
Vol. LVI (2018) Local Convergence Analysis of an Efficient Fourth Order Method 27

$\left(\mathcal{C}_{4}\right)$ there exist functions $w, v:\left[0, r_{0}\right) \longrightarrow \mathbb{R}_{+} \cup\{0\}$ with $w(0)=0$ such that for each $x, y \in D_{0}$ :

$$
\left\|F^{\prime}\left(x^{*}\right)^{-1}\left(F^{\prime}(x)-F^{\prime}(y)\right)\right\| \leq w(\|x-y\|)
$$

and

$$
\left\|F^{\prime}\left(x^{*}\right)^{-1} F^{\prime}(x)\right\| \leq v\left(\left\|x-x^{*}\right\|\right) ;
$$

$\left(\mathcal{C}_{5}\right)$ Condition $(2.2)$ holds;

$\left(\mathrm{C}_{6}\right) \bar{B}\left(x^{*}, r\right) \subset D$, where the radius of convergence $r$ is given by (2.4).

THEOREM 2.1. Suppose that the condition (e) hold. Then, the sequence $\left\{x_{n}\right\}$ generated for $x_{0} \in B\left(x^{*}, r\right)-\left\{x^{*}\right\}$ by method (1.1) is well defined in $B\left(x^{*}, r\right)$, remains in $B\left(x^{*}, r\right)$ for each $n=0,1,2, \ldots$ and converges to $x^{*}$. Moreover, the following estimates hold

$$
\left\|y_{n}-x^{*}\right\| \leq \varphi_{1}\left(\left\|x_{n}-x^{*}\right\|\right)\left\|x_{n}-x^{*}\right\| \leq\left\|x_{n}-x^{*}\right\|<r
$$

and

$$
\left\|x_{n+1}-x^{*}\right\| \leq \varphi_{2}\left(\left\|x_{n}-x^{*}\right\|\right)\left\|x_{n}-x^{*}\right\| \leq\left\|x_{n}-x^{*}\right\| .
$$

Furthermore, if there exists $R>r$ such that

$$
\int_{0}^{1} v(\theta R) d \theta<1
$$

then the limit point $x^{*}$ is the only solution of equation $F(x)=0$ in $D_{1}=$ $D \cap \bar{B}\left(x^{*}, R\right)$.

Proof. Estimates (2.6) and (2.7) shall be shown using mathematical induction. Using (2.1), $\left(\mathcal{C}_{3}\right)$ and the choice $x_{0} \in B\left(x^{*}, r\right)-\left\{x^{*}\right\}$ we have in turn that

$$
\left\|F^{\prime}\left(x^{*}\right)^{-1}\left(F^{\prime}\left(x_{0}\right)-F^{\prime}\left(x^{*}\right)\right)\right\| \leq w_{0}\left(\left\|x_{0}-x^{*}\right\|\right) \leq w_{0}(r)<1 .
$$

Estimate (2.9) and the Banach lemma on invertible operators $[2,18]$ give $F^{\prime}\left(x_{0}\right)$ is invertible and

$$
\left\|F^{\prime}\left(x_{0}\right)^{-1} F^{\prime}\left(x^{*}\right)\right\| \leq \frac{1}{1-w_{0}\left(\left\|x_{0}-x^{*}\right\|\right)} .
$$

Hence $y_{0}$ exists. By $\left(\mathcal{C}_{2}\right)$ we can write that

$$
F\left(x_{0}\right)=F\left(x_{0}\right)-F\left(x^{*}\right)=\int_{0}^{1} F^{\prime}\left(x^{*}+\theta\left(x_{0}-x^{*}\right)\right)\left(x_{0}-x^{*}\right) d \theta,
$$


where $x^{*}+\theta\left(x_{0}-x^{*}\right) \in B\left(x^{*}, r\right)$, since $\left\|x^{*}+\theta\left(x_{0}-x^{*}\right)-x^{*}\right\|=\theta\left\|x_{0}-x^{*}\right\|<r$ for each $\theta \in[0,1]$. Then, in view of the second inequality in $\left(\mathcal{C}_{4}\right)$ and $(2.11)$, we get that

$$
\left\|F^{\prime}\left(x^{*}\right)^{-1} F\left(x_{0}\right)\right\| \leq \int_{0}^{1} v\left(\theta\left\|x_{0}-x^{*}\right\|\right) d \theta\left\|x_{0}-x^{*}\right\|
$$

If follows from the first substep of method (1.1) for $n=0$ that

$$
y_{0}-x^{*}=\left(x_{0}-x^{*}-F^{\prime}\left(x_{0}\right)^{-1} F\left(x_{0}\right)\right)+\frac{1}{3} F^{\prime}\left(x_{0}\right)^{-1} F\left(x_{0}\right)
$$

Then, by (2.4), (2.5) (for $i=1),\left(\mathfrak{C}_{4}\right),(2.10),(2.12)$ and $(2.13)$, we have in turn that

$$
\begin{aligned}
\left\|y_{0}-x^{*}\right\| \leq & \left\|F^{\prime}\left(x_{0}\right)^{-1} F^{\prime}\left(x^{*}\right)\right\| \\
& \times\left\|\int_{0}^{1} F^{\prime}\left(x^{*}\right)^{-1}\left(F^{\prime}\left(x^{*}+\theta\left(x_{0}-x^{*}\right)\right)-F^{\prime}\left(x_{0}\right)\right)\left(x_{0}-x^{*}\right) d \theta\right\| \\
& +\frac{1}{3}\left\|F^{\prime}\left(x_{0}\right)^{-1} F^{\prime}\left(x^{*}\right)\right\|\left\|F^{\prime}\left(x^{*}\right)^{-1} F\left(x_{0}\right)\right\| \\
\leq & \left(\frac{\int_{0}^{1} w\left((1-\theta)\left\|x_{0}-x^{*}\right\|\right) d \theta+\frac{1}{3} \int_{0}^{1} v\left(\theta\left\|x_{0}-x^{*}\right\|\right) d \theta}{1-w_{0}\left(\left\|x_{0}-x^{*}\right\|\right)}\right)\left\|x_{0}-x^{*}\right\| \\
= & \varphi_{1}\left(\left\|x_{0}-x^{*}\right\|\right)\left\|x_{0}-x^{*}\right\| \leq\left\|x_{0}-x^{*}\right\|<r
\end{aligned}
$$

so (2.6) holds for $n=0$ and $y_{0} \in B\left(x^{*}, r\right)$. As in (2.10), we have for $y_{0}=x_{0}$ that $F^{\prime}\left(y_{0}\right)$ is invertible and

$$
\begin{aligned}
\left\|F^{\prime}\left(y_{0}\right)^{-1} F^{\prime}\left(x^{*}\right)\right\| & \leq \frac{1}{1-w_{0}\left(\left\|y_{0}-x^{*}\right\|\right)} \\
& \leq \frac{1}{1-w_{0}\left(\varphi_{1}\left(\left\|x_{0}-x^{*}\right\|\right)\left\|x_{0}-x^{*}\right\|\right)}
\end{aligned}
$$

We also have that $x_{1}$ exists. We can have by the second substep of method 
Vol. LVI (2018) Local Convergence Analysis of an Efficient Fourth Order Method 29

(1.1) for $n=0$ :

$$
\begin{aligned}
& x_{1}-x^{*} \\
= & x_{0}-x^{*}-F^{\prime}\left(x_{0}\right)^{-1} F\left(x_{0}\right)+\frac{3}{2} F^{\prime}\left(x_{0}\right)^{-1} F\left(x_{0}\right) \\
& -\frac{9}{8} F^{\prime}\left(y_{0}\right)^{-1} F^{\prime}\left(x_{0}\right)^{-1} F^{\prime}\left(x_{0}\right) F\left(x_{0}\right) \\
& -\frac{3}{8} F^{\prime}\left(x_{0}\right)^{-1} F^{\prime}\left(y_{0}\right) F^{\prime}\left(x_{0}\right)^{-1} F\left(x_{0}\right) \\
= & x_{0}-x^{*}-F^{\prime}\left(x_{0}\right)^{-1} F\left(x_{0}\right)+\frac{9}{8}\left(F^{\prime}\left(x_{0}\right)^{-1}-F^{\prime}\left(y_{0}\right)^{-1}\right) F\left(x_{0}\right) \\
& +\frac{3}{8} F^{\prime}\left(x_{0}\right)^{-1}\left(I-F^{\prime}\left(y_{0}\right) F^{\prime}\left(x_{0}\right)^{-1}\right) F\left(x_{0}\right) \\
= & x_{0}-x^{*}-F^{\prime}\left(x_{0}\right)^{-1} F\left(x_{0}\right) \\
& +\frac{9}{8} F^{\prime}\left(x_{0}\right)^{-1}\left[\left(F^{\prime}\left(y_{0}\right)-F^{\prime}\left(x^{*}\right)\right)+\left(F^{\prime}\left(x^{*}\right)-F^{\prime}\left(x_{0}\right)\right)\right] F^{\prime}\left(y_{0}\right)^{-1} F\left(x_{0}\right) \\
& +\frac{3}{8} F^{\prime}\left(x_{0}\right)^{-1}\left[\left(F^{\prime}\left(x_{0}\right)-F^{\prime}\left(x^{*}\right)\right)+\left(F^{\prime}\left(x^{*}\right)-F^{\prime}\left(y_{0}\right)\right)\right] F^{\prime}\left(x_{0}\right)^{-1} F\left(x_{0}\right) .
\end{aligned}
$$

By (2.4), (2.5) (for $i=2),(2.10)$ and (2.14)-(2.16), we get in turn that

$$
\begin{aligned}
& \left\|x_{1}-x^{*}\right\| \\
\leq & \left\|x_{0}-x^{*}-F^{\prime}\left(x_{0}\right)^{-1} F\left(x_{0}\right)\right\| \\
& +\frac{9}{8}\left\|F^{\prime}\left(x_{0}\right)^{-1} F^{\prime}\left(x^{*}\right)\right\|\left[\left\|F^{\prime}\left(x^{*}\right)^{-1}\left(F^{\prime}\left(y_{0}\right)-F^{\prime}\left(x^{*}\right)\right)\right\|\right. \\
& \left.+\left\|F^{\prime}\left(x^{*}\right)^{-1}\left(F^{\prime}\left(x^{*}\right)-F^{\prime}\left(x_{0}\right)\right)\right\|\right]\left\|F^{\prime}\left(y_{0}\right)^{-1} F^{\prime}\left(x^{*}\right)\right\|\left\|F^{\prime}\left(x^{*}\right)^{-1} F\left(x_{0}\right)\right\| \\
& +\frac{3}{8}\left\|F^{\prime}\left(x_{0}\right)^{-1} F^{\prime}\left(x^{*}\right)\right\|\left[\left\|F^{\prime}\left(x^{*}\right)^{-1}\left(F^{\prime}\left(x_{0}\right)-F^{\prime}\left(x^{*}\right)\right)\right\|\right. \\
& \left.+\left\|F^{\prime}\left(x^{*}\right)^{-1}\left(F^{\prime}\left(x^{*}\right)-F^{\prime}\left(y_{0}\right)\right)\right\|\right]\left\|F^{\prime}\left(x_{0}\right)^{-1} F^{\prime}\left(x^{*}\right)\right\|\left\|F^{\prime}\left(x^{*}\right)^{-1} F\left(x_{0}\right)\right\| \\
\leq \quad & \\
& \int_{0}^{1} w\left((1-\theta)\left\|x_{0}-x^{*}\right\|\right) d \theta\left\|x_{0}-x^{*}\right\| \\
& +\frac{9}{8} \frac{\left(w_{0}\left(\left\|x_{0}-x^{*}\right\|\right)+w_{0}\left(\left\|y_{0}-x^{*}\right\|\right)\right) \int_{0}^{1} v\left(\theta\left\|x_{0}-x^{*}\right\|\right) d \theta\left\|x_{0}-x^{*}\right\|}{\left(1-w_{0}\left(\left\|x_{0}-x^{*}\right\|\right)\right)\left(1-w_{0}\left(\left\|y_{0}-x^{*}\right\|\right)\right)} \\
& +\frac{3}{8} \frac{\left(w_{0}\left(\left\|x_{0}-x^{*}\right\|\right)+w_{0}\left(\left\|y_{0}-x^{*}\right\|\right)\right) \int_{0}^{1} v\left(\theta\left\|x_{0}-x^{*}\right\|\right) d \theta\left\|x_{0}-x^{*}\right\|}{\left(1-w_{0}\left(\left\|x_{0}-x^{*}\right\|\right)\right)^{2}} \\
\leq & \varphi_{2}\left(\left\|x_{0}-x^{*}\right\|\right)\left\|x_{0}-x^{*}\right\| \leq\left\|x_{0}-x^{*}\right\|<r
\end{aligned}
$$


so (2.7) holds and $x_{1} \in B\left(x^{*}, r\right)$. The induction for (2.6) and (2.7) can be completed if we replace $x_{0}, y_{0}, x_{1}$ by $x_{k}, y_{k}, x_{k+1}$ in the preceding estimates. Then by the estimate

$$
\left\|x_{k+1}-x^{*}\right\| \leq c\left\|x_{k}-x^{*}\right\|<r
$$

where $c=\varphi_{2}\left(\left\|x_{0}-x^{*}\right\|\right) \in[0,1)$, we deduce that $\lim _{k \longrightarrow \infty} x_{k}=x^{*}$ and $x_{k+1} \in B\left(x^{*}, r\right)$. Finally, the uniqueness of the solution $x^{*}$ in $D_{1}$ can be shown by defining $Q=\int_{0}^{1} F^{\prime}\left(x^{*}+\theta\left(y^{*}-x^{*}\right)\right) d \theta$ where $y^{*} \in D_{1}$ with $F\left(y^{*}\right)=0$. Using $\left(\mathcal{C}_{1}\right)$ and $(2.8)$ we obtain in turn that

$$
\left\|F^{\prime}\left(x^{*}\right)^{-1}\left(Q-F^{\prime}\left(x^{*}\right)\right)\right\| \leq \int_{0}^{1} v\left(\theta\left\|x^{*}-y^{*}\right\|\right) d \theta \leq \int_{0}^{1} v(\theta R) d \theta<1,
$$

so linear operator $Q$ is invertible. Then, the identity

$$
0=F\left(x^{*}\right)-F\left(y^{*}\right)=Q\left(x^{*}-y^{*}\right),
$$

we get that $x^{*}=y^{*}$.

$R E M A R K$ 2.2. (a) In the case when $w_{0}(t)=L_{0} t, w(t)=L t$ and $D_{0}=D$, the radius $r_{A}=\frac{2}{2 L_{0}+L}$ was obtained by Argyros in [11] as the convergence radius for Newton's method under conditions $\left(\mathcal{C}_{1}\right)-\left(\mathcal{C}_{2}\right)$. Notice that the convergence radius for Newton's method given independently by Rheinboldt [18] and Traub [22] is given by

$$
\rho=\frac{2}{3 L}<r_{A}
$$

As an example, let us consider the function $f(x)=e^{x}-1$. Then $x^{*}=0$. Set $\Omega=B(0,1)$. Then, we have that $L_{0}=e-1<L=e$, so $\rho=0.24252961<r_{A}=0.324947231$.

Moreover, the new error bounds [2] are:

$$
\left\|x_{n+1}-x^{*}\right\| \leq \frac{L}{1-L_{0}\left\|x_{n}-x^{*}\right\|}\left\|x_{n}-x^{*}\right\|^{2},
$$

whereas the old ones $[18,22]$

$$
\left\|x_{n+1}-x^{*}\right\| \leq \frac{L}{1-L\left\|x_{n}-x^{*}\right\|}\left\|x_{n}-x^{*}\right\|^{2} .
$$

Clearly, the new error bounds are more precise, if $L_{0}<L$. Clearly, we do not expect the radius of convergence of method (1.1) given by $r_{3}$ to be larger than $r_{A}$. 
Vol. LVI (2018) Local Convergence Analysis of an Efficient Fourth Order Method 31

(b) The local results can be used for projection methods such as Arnoldi's method, the generalized minimum residual method(GMREM), the generalized conjugate method(GCM) for combined Newton/finite projection methods and in connection to the mesh independence principle in order to develop the cheapest and most efficient mesh refinement strategy $[1,7]$.

(c) Let $\mathcal{B}_{1}=\mathcal{B}_{2}=\mathbb{R}$. The results can be also be used to solve equations where the operator $F^{\prime}$ satisfies the autonomous differential equation $[2-5]$ :

$$
F^{\prime}(x)=P(F(x))
$$

where $P: \mathcal{B}_{1} \longrightarrow \mathcal{B}_{2}$ is a known continuous operator. Since $F^{\prime}\left(x^{*}\right)=$ $P\left(F\left(x^{*}\right)\right)=P(0)$, we can apply the results without actually knowing the solution $x^{*}$. Let as an example $F(x)=e^{x}-1$. Then, we can choose $P(x)=x+1$ and $x^{*}=0$.

(d) It is worth noticing that method (1.1) are not changing if we use the new instead of the old conditions [19]. Moreover, for the error bounds in practice we can use the computational order of convergence (COC)

$$
\xi=\frac{\ln \frac{\left\|x_{n+2}-x^{*}\right\|}{\left\|x_{n+1}-x^{*}\right\|}}{\ln \frac{\left\|x_{n+1}-x^{*}\right\|}{\left\|x_{n}-x^{*}\right\|}}, \quad \text { for each } n=1,2, \ldots
$$

or the approximate computational order of convergence (ACOC)

$$
\xi^{*}=\frac{\ln \frac{\left\|x_{n+2}-x_{n+1}\right\|}{\left\|x_{n+1}-x_{n}\right\|}}{\ln \frac{\left\|x_{n+1}-x_{n}\right\|}{\left\|x_{n}-x_{n-1}\right\|}}, \quad \text { for each } n=0,1,2, \ldots
$$

(e) In view of $\left(\mathcal{C}_{3}\right)$ and the estimate

$$
\begin{aligned}
\left\|F^{\prime}\left(x^{*}\right)^{-1} F^{\prime}(x)\right\| & =\left\|F^{\prime}\left(x^{*}\right)^{-1}\left(F^{\prime}(x)-F^{\prime}\left(x^{*}\right)\right)+I\right\| \\
& \leq 1+\left\|F^{\prime}\left(x^{*}\right)^{-1}\left(F^{\prime}(x)-F^{\prime}\left(x^{*}\right)\right)\right\| \\
& \leq 1+w_{0}\left(\left\|x-x^{*}\right\|\right)
\end{aligned}
$$

the second condition in $\left(\mathfrak{C}_{4}\right)$ can be dropped to be replaced by

$$
v(t)=1+w_{0}(t)
$$

or

$$
v(t)=1+w_{0}\left(r_{0}\right),
$$

since $t \in\left[0, r_{0}\right)$. 
(f) Condition (2.2) can be dropped if we define parameter $d$ by

$$
d:=\varphi_{1}\left(r_{2}\right) r_{2}
$$

and the ball $B\left(x^{*}, r^{*}\right)$, where

$$
r^{*}=\max \left\{d, r_{2}\right\} .
$$

Suppose that

$\left(\mathrm{C}_{5}^{\prime}\right) \bar{B}\left(x^{*}, r^{*}\right) \subseteq D$

Denote by $\left(\mathfrak{C}^{\prime}\right)$ conditions $\left(\mathfrak{C}_{1}\right),\left(\mathfrak{C}_{2}\right),\left(\mathfrak{C}_{3}\right),\left(\mathfrak{C}_{4}\right)$ and $\left(\mathfrak{C}_{5}^{\prime}\right)$. Then, we have :

THEOREM 2.3. Suppose that the conditions $\left(\mathrm{C}^{\prime}\right)$ hold. Then, the conclusions of Theorem 2.1 hold except (2.6) which is replaced by

$$
\left\|y_{n}-x^{*}\right\| \leq \varphi_{1}\left(\left\|x_{n}-x^{*}\right\|\right)\left\|x_{n}-x^{*}\right\| \leq d .
$$

Proof. By simply following the proof of Theorem 2.1 and using (2.22) and $\left(\mathfrak{C}_{5}^{\prime}\right)$ we arrive at $(2.22)$ instead of $(2.6)$. The rest of the proof as identical to the one in Theorem 2.1 is omitted.

\section{$3 \quad$ Numerical Examples}

We present two examples in this section.

EXAMPLE 3.1. Let $\mathcal{B}_{1}=\mathcal{B}_{2}=\mathbb{R}^{3}, D=\bar{U}(0,1), x^{*}=(0,0,0)^{T}$. Define function $F$ on $D$ for $w=(x, y, z)^{T}$ by

$$
F(w)=\left(e^{x}-1, \frac{e-1}{2} y^{2}+y, z\right)^{T} .
$$

Then, the Fréchet-derivative is given by

$$
F^{\prime}(v)=\left[\begin{array}{ccc}
e^{x} & 0 & 0 \\
0 & (e-1) y+1 & 0 \\
0 & 0 & 1
\end{array}\right]
$$

Using $\left(\mathcal{C}_{1}\right)-\left(\mathfrak{C}_{4}\right)$, we can choose $w_{0}(t)=L_{0} t, w(t)=e^{\frac{1}{L_{0}}} t, v(t)=e^{\frac{1}{L_{0}}}, L_{0}=$ $e-1$.

Then, the radius of convergence $r$ is given by

$$
r_{1}=0.1544, r_{2}=0.0183=r .
$$


Vol. LVI (2018) Local Convergence Analysis of an Efficient Fourth Order Method 33

EXAMPLE 3.2. Returning back to the motivational example given at the introduction of this study, we can choose (see also Remark 2.2 (e) for function v) $w_{0}(t)=w(t)=\frac{1}{8}\left(\frac{3}{2} \sqrt{t}+t\right)$ and $v(t)=1+w_{0}\left(r_{0}\right), r_{0} \simeq 4.7354$. Then, the radius of convergence $r$ is given by

$$
r_{1}=0.5092, r_{2}=0.00000009=r .
$$

\section{References}

[1] S. Amat, S. Busquier, and M. Negra, Adaptive approximation of nonlinear operators, Numer. Funct. Anal. Optim. 25, (2004), 397-405

[2] I.K. Argyros, Computational theory of iterative methods, Series: Studies in Computational Mathematics, 15, Editors: C.K.Chui and L. Wuytack, Elsevier Publ. Co. New York, U.S.A, (2007)

[3] I.K. Argyros and H. Ren, Improved local analysis for certain class of iterative methods with cubic convergence, Numerical Algorithms, 59, (2012), 505-521

[4] I. K. Argyros, Yeol Je Cho, and S. George, Local convergence for some thirdorder iterative methods under weak conditions, J. Korean Math. Soc. 53 (4), (2016), $781-793$

[5] I. K. Argyros and S. George, Ball convergence of a sixth order iterative method with one parameter for solving equations under weak conditions, ISSN 0008-0624, Calcolo, DOI 10.1007/s10092-015-0163-y

[6] I.K. Argyros and A. A. Magreñán, Local convergence analysis of proximal GaussNewton method for penalized nonlinear least square problems, Appl. Math. Comput.V. 241, 15, (2014), 401-408

[7] I.K. Argyros and F. Szidarovszky, The theory and Applications of Iterative methods, CRC Press, Boca Raton Florida, USA, (1993)

[8] A. Cordero, J. Hueso, E. Martinez, and J.R. Torregrosa, A modified NewtonJarratt's composition, Numer. Algor. 55, (2010), 87-99

[9] A. Cordero and J.R. Torregrosa, Variants of Newton's method for functions of several variables, Appl.Math. Comput. 183, (2006), 199-208

[10] A. Cordero and J.R. Torregrosa, Variants of Newton's method using fifth order quadrature formulas, Appl.Math. Comput. 190, (2007), 686-698

[11] J.M. Gutiérrez and M.A. Hernández, Newton's method under weak Kantorovich conditions, IMA J. Numer. Anal. 20, (2000), 521-532

[12] G.M Grau-Sanchez, A. Grau, and M. Noguera, On the computational efficiency index and some iterative methods for solving systems of non-linear equations, $J$. Comput. Appl Math. 236, (2011), 1259-1266

[13] H.H. Homeier, A modified Newton method with cubic convergence,the multivariable case, J.Comput.Appl.Math. 169, (2004), 161-169 
[14] H.H. Homeier, On Newton type methods with cubic convergence, J.Comput.Appl.Math. 176, (2005), 425-432

[15] J.S Kou, Y.T. Li, and X.H. Wang, A modification of Newton method with fifthorder convergence, J. Comput. Appl. Math. 209, (2007), 146-152

[16] M.A. Noor and M. Waseem, Some iterative methods for solving a system of nonlinear equations, Computers and Mathematics with Applications, 57, (2009), 101106

[17] A.N. Romero, J.A. Ezquerro, and M.A. Hernandez, Approximacion de soluciones de algunas equacuaciones integrals de Hammerstein mediante metodos iterativos tipo. Newton, XXI Congresode ecuaciones diferenciales y aplicaciones Universidad de Castilla-La Mancha, (2009)

[18] W.C. Rheinboldt, An adaptive continuation process for solving systems of nonlinear equations, Mathematical models and numerical methods (A.N.Tikhonov et al. eds.) pub.3, (1977), 129-142

[19] J.R. Sharma, R.K. Guha, and R. Sharma, An efficient fourth order weightedNewton method for systems of nonlinear equations, Numer. Algor. 62, (2013), 307323

[20] J.R. Sharma and P.K Gupta, An efficient fifth order method for solving systems of nonlinear equations, Comput. Math. Appl. 67, (2014), 591-601

[21] F.A. Shah and M.A Noor, Some numerical methods for solving nonlinear equations by using decomposition technique, Appl. Math. Comput. 251, (2015), 378-386

[22] J.F. Traub, Iterative methods for the solution of equations, AMS Chelsea Publishing, (1982)

Received: 20.09.2016

Accepted: 4.11.2017

Revised: 8.10.2017 